\title{
The UEFA model in identification of types, severity and mechanism of injuries among professional footballers in the Nigerian Premier League
}

\author{
U K Ani, ${ }^{1}$ MSc; P O Ibikunle, ${ }^{2,3} \mathrm{PhD}$; C O Akosile, ${ }^{3} \mathrm{PhD}$; U Useh, ${ }^{2} \mathrm{PhD}$ \\ ${ }^{1}$ Physiotherapy Department, College of Health Sciences, Babcock University Teaching Hospital, Ilisan-Remo, Nigeria \\ ${ }^{2}$ School of Research and Postgraduate Studies, Faculty of Agriculture, Science and Technology, North-West University, Mafikeng, South Africa \\ ${ }^{3}$ Department of Medical Rehabilitation, Faculty of Health Sciences and Technology, Nnamdi Azikiwe University, Nnewi, Nigeria
}

Corresponding author: P O Ibikunle (po.ibikunle@unizik.edu.ng)

\begin{abstract}
Background. Association football, otherwise known as soccer, is the most popular sport in the world. The increase in the popularity of the game and the expectations from players make injury risk in football high.

Objective. To describe the types, severity, prevalence and mechanism of injuries among professional footballers in the Nigeria Premier League (NPL).

Methods. The Union of European Football Association (UEFA) Injury Study Questionnaire was used for data collection. A total of 240 footballers from 11 clubs, who participated in the 2011/2012 NPL premiership season, was selected through proportionate stratified random sampling technique, and the participants were studied using a prospective cohort study design for 6 months. Descriptive statistics of means, percentages and frequency distributions were used to answer the research questions.

Results. The mean (standard deviation) age, height and weight of the injured footballers was 22.9 (3.4) years, $1.69(0.05) \mathrm{m}$ and 71.3 (3.9) $\mathrm{kg}$, respectively. There was a high injury prevalence (78\%) associated with actual league games, whereas the incidence rate per 1000 -hour exposure was 300.2 exposure-hours from 19 games within 6 months. Sprain (32\%) was the predominant type of injury recorded. The tackle event (34\%) was the predominant mechanism of injury recorded, and $63 \%$ of the injuries led to 1 - 3 days of player absence from football activities. Most of the injuries were recurrent injuries (63\%).

Conclusion. This study showed a high occurrence of injuries in the NPL, in particular associated with league (competitive) games. The findings of this study will serve to guide the development and implementation of injury prevention strategies in the NPL.

S Afr J Sports Med 2015;27(1):12-15. DOI:10.7196/SAJSM.514
\end{abstract}

Association football, or soccer, is the most popular sport in the world, played by 265 million footballers. ${ }^{[1]}$ In Africa, football is governed by Confederation of African Football (CAF), an organisation that was formed in 1957 by four founding members - Egypt, Sudan, Ethiopia and South Africa - to administer and organise football activities on the continent.

Football started in Nigeria in the early 1900s, and was introduced by Baron Mulford, who organised weekly matches between European and Nigerian youths in Lagos. ${ }^{[2]}$ The Nigerian Football Association (NFA) was established in 1945 with the Governor's Cup, which later became known as the Football Association (FA) Cup - the major national domestic football competition. ${ }^{[2,3]}$ In 1972, the National League was formed with six teams, and in 1990, at Onikan Stadium in Lagos state, the Professional League was launched, with 16 clubs from around the country. ${ }^{[2,4]}$ Today, the Nigeria Premier League (NPL) is the highest level of domestic Nigerian football, organised and managed by the Nigeria Professional League Board (NPLB). ${ }^{[3]}$ The NPL is ranked above two first-division groups: the Nigeria Division 1-A and Nigeria Division 1-B. ${ }^{[2]}$

Football is associated with a variety of injuries and a high injury incidence rate. These factors are primarily due to the popularity of the game and the performance-related pressure placed on the players ${ }^{[5]}$ A football injury is a physical complaint sustained by a player during competition or training, preventing the player from participating in competition or training activities for one or more days thereafter ${ }^{[6,7]}$ Injuries sustained in football are due to a combination of factors (intrinsic and extrinsic). These include the nature of the sporting environment, equipment and rules, and the unique physical characteristic of the footballers, such as structural imbalances and age. ${ }^{[8]}$ Sports injuries are expected consequences of competitions and are not usually as a result of a single causative factor, but are instead associated with various factors interacting at a given time. ${ }^{[9]}$ Types of injury classifications may also depend on anatomical structures and the specific areas involved, including musculoskeletal, neurological and lower-back injuries. The musculoskeletal classification may involve skeletal muscles, joints, tendons and ligaments. Musculoskeletal injuries constitute the largest class of injuries sustained in sport.

Based on previous epidemiological injury research, the severity of an injury may be categorised into mild, moderate, major, sportsdisabling and catastrophic. ${ }^{[9]} \mathrm{A}$ recent epidemiological study of football injuries in Benin City, Nigeria, showed an $~ 82 \%$ injury prevalence rate among footballers. ${ }^{[5]}$ Studies using video analysis to compare injury prevalence between Nigerian and English professional soccer leagues have found that the NPL had a higher occurrence of injuries than the English Premier League. ${ }^{[5,10]}$ There is a lack of injury 
epidemiological research on professional Nigerian footballer cohorts, and furthermore, there are inconsistencies in the way injuries are reported. ${ }^{[5]}$ The UEFA model/guideline is a policy model and a practical guideline for conducting epidemiological studies of football injuries, and was designed to correct the inconsistent manner in which epidemiological studies were conducted in football. ${ }^{[11]}$ These inconsistencies include football injury definitions that differ between studies, and varying research designs that make data comparison difficult. ${ }^{[1]]}$ The model states that a football injury study should have a prospective cohort design, and that the study should cover both training and competition sessions. The model also stipulates that information about football injuries should include date of injury, date of return to football activities, injury types, location of injury, mechanism of injury and a measure of severity. In the guideline, injury severity is categorised as slight (1 3 days' absence), minor ( $4-7$ days), moderate ( 8 - 28 days), and major ( $>28$ days). In addition, the model stipulates that only injuries occurring during scheduled team activities should be included in the statistics, while injuries that occurred during leisure time or from participating in other sports (outside team training or matches), and absence as a result thereof, should not be included. ${ }^{[6]}$ It is evident that in the NPL, there is a paucity of information on the injury profile of the footballers and that there is no comprehensive database for injuries in the league. ${ }^{[5,10]}$ This may limit the opportunity for the design and implementation of targeted injury prevention strategies, and may inhibit the growth and development of the game in Nigeria. These inconsistencies have made it difficult to meaningfully compare published studies on types, severity and mechanisms of injury, and injury prevalence.

The objectives of this study were to determine among professional footballers in the NPL: (i) the prevalence rate of injuries; (ii) the predominant types of injuries; (iii) the severity of injuries; and (iv) the incidence rate of injuries during matches (expressed as per 1000 match player-hours).

\section{Methodology}

\section{Research design}

This study was a prospective cohort survey. Professional league players were prospectively monitored for a period of 6 months.

\section{Population}

The target population of the study was (30 players per club), who participated in the 2011/2012 NPL season.

\section{Sample size}

A total of 240 players constituted the sample. They were randomly selected from 11 clubs of 30 registered players each. The sample size was statistically determined using the Taro Yamane formula for a finite population. ${ }^{[12]}$

\section{Sampling technique}

Proportionate stratified random sampling was used for this study (Table 1).

\section{Instrument for data collection}

The UEFA injury study questionnaire was used for data collection. The instrument has a reliability coefficient of 0.80 and a validity coefficient of 0.89 . The questionnaire has 17 categories of questions. Information collected from the footballers included anthropometric data, exposure types, game situations, training/match surfaces, injury types, injury locations, mechanisms of injury, injury severity and referee sanctions. The instrument was interpreted by coding each item with Arabic numerals and the frequency of each categorical variable was calculated.

\section{Method/procedures of data collection}

Ethical approval for the study was sought and obtained from the University Teaching Hospital Ethical Committee. The 2011/12 NPL season was studied for 6 months. Club officials and medical personnel were recruited and trained at participating clubs to serve as research assistants. The purpose, procedures and ethical components of the research were also fully explained to the participants. The research assistants and the 600 professional footballers from 20 clubs

researchers distributed the questionnaires to the clubs. The players completed the forms after relevant explanations/instructions by the researchers and trained research assistants. Where this was not possible, the research assistants administered the questionnaire to the footballers. The researchers were in contact with the clubs and research assistants telephonically, and received completed questionnaires either by physically collecting them at each club or via mail at the end of each month. Injury cards/questionnaires were mailed to the study group on the last day of every month.

\section{Definition of injury}

An injury was defined as any event occurring during a scheduled training session or a match, resulting in the player leaving that session/ match or missing a subsequent session/match. Recurrent injury was defined as any event occurring during a scheduled training session or match in sequel to an injury that was not adequately rehabilitated, resulting in the player leaving that session/match or missing a subsequent session/match. Absence from training sessions and matches due to injury were reported on the attendance record and an injury report form was completed.

\section{Severity of injuries and illnesses}

The severity of an injury or illness episode was evaluated by the length of absence from football participation.

\section{Rehabilitation}

A player was considered rehabilitated if he could fully participate in all aspects of collective training (Table 2). The player was considered fully rehabilitated once the medical team had cleared him for full participation in team training and availability for match selection.

Table 1. Regional distribution and selection of professional league clubs

\begin{tabular}{lllll}
\hline Geopolitical region & Clubs, $\boldsymbol{n}$ & $\begin{array}{l}\text { Population of } \\
\text { players, } \boldsymbol{n}\end{array}$ & $\begin{array}{l}\text { Selected clubs } \\
\text { based on } \\
\text { sampling, } \boldsymbol{n}\end{array}$ & Sample size, $\boldsymbol{n}$ \\
\hline South-West & 3 & 90 & 2 & 36 \\
South-East & 3 & 90 & 2 & 36 \\
South-South & 5 & 150 & 2 & 60 \\
North-East & 2 & 60 & 1 & 24 \\
North-Central & 4 & 120 & 2 & 48 \\
North-West & 3 & 90 & 2 & 36 \\
Total & 20 & 600 & 11 & 240
\end{tabular}




\section{Confidentiality}

All personal data were confidential. The names of all the players involved in the study were replaced by codes before computerising. The contact person in each club replaced the names of individual players with a code and deleted the players' names before sending the forms to the investigators.

\section{Method of data analysis}

Descriptive statistics of means, standard deviation (SDs) and frequencies were used as statistical tools to describe the footballers' anthropometric characteristics and other variables. Percentages and frequencies were used to answer the research questions. The prevalence rate was extrapolated using the following formula:

Prevalence $=$ number of injuries recorded $/$ sample size $\times 100$

The following formula was used to calculate the incident rate/ 1000 hours of player exposure: ${ }^{[13]}$

Match-related injury incidence $=[$ number of injuries $\times 1000] /[$ player exposure hours]

Incidence rates were described as the number of new injuries in a population at risk over a specified time period, or the number of new injuries during a period divided by the total number of players in that period.

Results

Anthropometric characteristics of injured players

The mean (SD) age of the injured footballers in this study was 22.9 (3.4) years (range 16 - 31) and their mean height, body mass and body mass index was $1.69(0.05) \mathrm{m}, 71.3(3.9) \mathrm{kg}$, and $24.6(1.6) \mathrm{kg} . \mathrm{m}^{-2}$, respectively.

\section{Prevalence rate, type and severity of} injuries

The prevalence rate of injuries among the professional footballers was $78 \%$, with the predominant type of injury being ligament sprain injuries (32\%) (Table 3). Muscle rupture/tear and tendon injuries constituted $17 \%$ and $7 \%$ of all the recorded injuries, respectively. Haematoma/contusion/bruises accounted for $6 \%$ of the injuries, while synovitis/effusion, overuse symptoms, abrasion and lacerations each accounted for $4 \%$ of injuries. Overall, $63 \%$ of the injuries sustained were of a 'slight' severity, resulting in 1 3 days' absence from team football activities.
Table 2. Frequency of injuries occurring during different activities

\begin{tabular}{ll}
\hline & $\boldsymbol{n}(\%)$ \\
\hline League match & $98(49)$ \\
Football training & $71(38)$ \\
Friendly match & $7(6)$ \\
Other training & $6(3)$ \\
National team training & $2(1)$ \\
$\begin{array}{l}\text { Reserve/youth team } \\
\text { training }\end{array}$ & $3(2)$ \\
Total & $187(100)^{*}$ \\
$*$ *ercentages are rounded therefore may not total 100 exactly.
\end{tabular}

Severe injuries ( $>28$ days lost) constituted $14 \%$ of injuries, while moderate injuries (8 - 28 days' absence from football activities) and minor injuries (4 - 7 days' absence) constituted $14 \%$ and $9 \%$, respectively.

\section{Frequency of injuries occurring during} different activities

Most of the injuries occurred during matches (49\%) and practices (38\%) (Table 2).

Distribution of injuries according to mechanisms, playing surfaces and recurrent injury incidences

Tackle events (34\%) and falling/diving (8\%) were the predominant injury mechanisms (Table 4). Other injury mechanisms included running/sprinting and stretching, accounting for $7 \%$ each, and twisting/ turning and sliding, which accounted for $6 \%$ each. About $69 \%$ of injuries occurred while playing on grass surface, $28 \%$ on an artificial surface, and $3 \%$ on other surfaces. Approximately $37 \%$ of all the injuries were recurrent injuries, which affected the same body parts, while $63 \%$ of the injuries were first-time injuries.

\section{Calculation of risk of injury}

A total of 187 injuries were recorded. There were 22 players per match and 19 matches during the study period. The average match duration was 1.49 hours. Therefore, the exposure time during matches was calculated as:

22 players $\times 19$ games $\times 1.49$ playing hours $=622.82$ player exposure hours

Therefore, the risk during matches was calculated as:

(187 injuries/622.82 player exposure hours) $\times 1000=300.2$ injuries $/ 1000$ player-hours
Table 3. Types of injury

\begin{tabular}{ll}
\hline & $\boldsymbol{n}(\%)$ \\
\hline Sprain & $60(32)$ \\
Muscle rupture/tear & $33(17)$ \\
Others & $16(9)$ \\
Tendon injury/tendonosis & $13(7)$ \\
Haematoma/contusion/bruises & $11(6)$ \\
Synovitis/effusion & $8(4)$ \\
Overuse symptoms & $8(4)$ \\
Dislocation/subluxation & $8(4)$ \\
Abrasion & $7(4)$ \\
Laceration & $7(4)$ \\
Dental injury & $7(4)$ \\
Lesion of meniscus/cartilage & $7(4)$ \\
Fracture & $2(1)$ \\
Other bone injuries & $1(1)$ \\
Total & $180(100)^{\star}$
\end{tabular}

*Percentages are rounded therefore may not total 100 exactly.

Table 4. Mechanism of injury

\begin{tabular}{ll}
\hline & $\boldsymbol{n}(\%)$ \\
\hline Tackle event & $63(34)$ \\
Falling/diving & $14(8)$ \\
Running/sprinting & $13(7)$ \\
Stretching & $13(7)$ \\
Twisting/turning & $12(6)$ \\
Sliding & $12(6)$ \\
Shooting & $11(6)$ \\
Collision & $10(5)$ \\
Heading & $10(5)$ \\
Jumping/landing & $6(3)$ \\
Blocked & $5(3)$ \\
Dribbling & $5(3)$ \\
Use of arm or elbow & $4(2)$ \\
Hit by ball & $4(2)$ \\
Kicked by other players & $3(2)$ \\
Overuse & $2(1)$ \\
Total & $187(100)^{*}$ \\
$*$ Percentages are rounded therefore may not total 100 exactly. &
\end{tabular}

\section{Discussion}

This study revealed an injury prevalence rate of $78 \%$ among professional footballers in the NPL. This result is consistent with the findings of other authors, ${ }^{[5,10]}$ who found sports injury prevalence rates of $68 \%$ and $82 \%$, respectively, among the footballers in 
NPL. However, these findings are in contrast to the findings in some previous studies, ${ }^{[6,9]}$ which found much lower injury prevalence rates in footballers. The difference between our results and the latter might be in the different approaches to winning of the clubs/players, the research methodologies used and the different experience/skills of players who participated in the studies. ${ }^{[14-16]}$ Moreover, injured players in the NPL were not promptly and properly attended to medically, resulting in increased incidences of recurrent injuries among the players. ${ }^{[5,11]}$ The differences might also be suggestive of the competitive nature of the game, and underscore the need for good officiating/stricter refereeing, adherence to the principle of fair play by the clubs and players, adequate warm-up, safe and effective techniques by the players, and improved coaching techniques on injury prevention. The incidence of injury (300.2 injuries/ 1000 player-hours) was relatively higher than those previously recorded in European and American professional footballers. ${ }^{[6,17,18]}$

The finding that there were more injuries in league matches/ competitions (49\%) than during training (38\%) has been reported before. ${ }^{[5]}$ This can be attributed to the higher intensity of play during matches/competitions compared with training.

Recurrent injuries constituted $37 \%$ of all the injuries recorded in this study. This differs from a previous study, which reported that recurrent injuries constituted $\sim 7 \%$ of all injuries. ${ }^{[19]}$ The high rate of recurrent injuries among the players in the NPL can be attributed to premature return to football activities after injury, without adequate rehabilitation, or overloading of the players with too many matches. We observed that although most of the clubs studied had masseurs attached to their teams, few clubs had other medical staff, including physiotherapists. This may have resulted in limited rehabilitation regimens within the club, which may have resulted in inadequate rehabilitations after injury.

High incidences of previous injury have been reported to be a predisposing factor to future injuries in football. ${ }^{[17-19,20]}$ Recent research proposes the need to differentiate between exacerbations and recurrent injuries, ${ }^{[19-22]}$ as this would enable researchers to investigate risk factors for these two types of recurrent injuries separately. This would also determine how well players have been rehabilitated before returning to full participation. ${ }^{[17-19]}$

The data on time loss due to injury showed that $\sim 63 \%$ of the injuries were of a slight severity, leading to about 1 - 3 days' absence from matches and training, while $\sim 14 \%$ of the injuries were severe injuries, leading to $\geq 28$ days' absence from organised team activities (matches and training). Lesser injury severity has been reported in previous studies. ${ }^{[18]}$ The higher number of days lost to injuries in this study may be attributable to the lack of proper medical attention given to the players when they were injured. ${ }^{[11,17]}$

This study showed that the prevalence of injuries in league matches and football training is $49 \%$ and $38 \%$, respectively. It also revealed that tackle events (34\%) were the predominant cause of injury in both matches and training. This finding may allude to the aggressiveness of some footballers, as was suggested in a recent study; ${ }^{[22]}$ our study did not formally evaluate the aggression of the NPL footballers. However, the frequency of tackle events in soccer compared with other events such as heading or shooting may also be responsible for tackling being a predominant injury mechanism.

\section{Conclusion}

This study showed a high occurrence of injuries in the NPL, in particular associated with actual league (competitive) games. Defenders sustained the most injuries, often from tackle events. This may be a result of attackers being more aggressive in their bid to score goals, to the point of inflicting injuries on the defenders, or that defenders take greater risks to avert goals being scored against their teams. The findings of this study will serve to guide the development and implementation of injury prevention strategies in the NPL.

\section{References}

1. Fédération Internationale de Football Association. Big count. http://www.fifa.com/ worldfootball/bigcount/index.html (accessed 30 January 2014).

2. Rahama AA. Nigeria National League. http://www.nigerianationalleague.com/aboutthe-league (accessed 30 May 2013)

3. Online Nigeria. History of sport in Nigeria. http://www.onlinenigeria.com/sport (accessed 4 March 2015).

4. Schöggl H. Nigeria 1972 - 1979. http://www.rsssf.com/tablesn/nig72.html (accessed 18 January 2012).

5. Azubuike SO, Okojie OH. An epidemiological study of football (soccer) injuries in Benin City Nigeria. Br J Sports Med 2009;43(5):382-386. [http:/dx.doi.org/10.1136/bjsm.2008.051565]

6. Hägglund M, Walden M, Ekstrand, J. Injury prediction in professional football. Abstract, First World Congress of Sports Injury Prevention. Br J Sports Med 2005;39(6):375-408

7. Fuller CW, Randall WD, Corllette J, Schmalz R. Comparison of the incidences, nature and cause of injuries sustained on grass and new generation artificial turf by male and female football players. Part 2: Training injuries. Br J Sports Med 2007;41(Suppl 1):27-32. [http://dx.doi.org/10.1136/bjsm.2007.037267]

8. Hootman JM. Epidemiology of musculoskeletal injuries among sedentary and physically active adults. Med Sci Sports Exerc 2002;34(5):838-844. [http://dx.doi. org/10.1097/00005768-200205000-00017]

9. Hägglund M, Walden M, Bahr R, Ekstrand J. Methods for epidemiological study of injuries to professional football players: Developing the UEFA model. Br J Sports Med 2005;39(6):340-346. [http://dx.doi.org/10.1136/bjsm.2005.018267]

10. Akinbo SR, Salau MA, Odebiyi DO, Ibeabuchi NM. Video analysis of musculoskeletal injuries in nigeria and english professional soccer leagues. Niger J Health Biomed Sci 2007;6(2):85-89.

11. Ekstrand J, Vogel U. EURO 2004 injury study. Abstract, First World Congress of Sports Injury Prevention. Br J Sports Med 2004;39(6):373-408.

12. Uzoagulu AE. Practical Guide to Writing Research Project Reports in Tertiary Institutions. Enugu: Cheston Ltd, 2011.

13. Philips LH. Sports injury incidence. Br J Sports Med 2000;34(2):133-136. [http:// dx.doi.org/10.11.36/bjsm.34.2.133]

14. Faude O, Junge A, Kindermann W. Injuries in elite female soccer players. Abstract First World Congress of Sports Injury Prevention. Br J Sports Med 2005;39(6):375408.

15. Emery CA, Meeuwisse WH, Hartmann S. Risk factors for injury in adolescent soccer: Implementation and validation of an injury surveillance system. Abstract, First World Congress of Sports Injury Prevention. Br J Sports Med 2005;39(6):375-408.

16. Junge A, Rösch D, Peterson L, Graf-Baumann T, Dvorak J. Prevention of soccer injuries: A prospective intervention study in youth armature players. Am J Sports Med 2002;30(5):652-659.

17. Dvorak J, Junge A, Derman W, Schwellnus M. Injuries and illnesses of football players during the 2010 FIFA World Cup. Br J Sports Med 2011;45(8):626-630. [http://dx.doi. org/10.1136/bjsm.2010.079905]

18. Ekstrand J, Gillquist J, Möller M, Oberg B, Liljedahl SO. Incidences of soccer injuries and their relation to training and team success. Am J Sports Med 1983;11(2):63-67. [http://dx.doi.org/10.1177/036354658301100203]

19. Meeuwisse WH. Assessing causation in sport injury: A multifactorial approach. Clin J Sport Med 1999;4(3):166-170. [http://dx.doi.org/10.1097/00042752-19940700000004]

20. Hawkins D, Metheny J. Overuse injuries in youth sports: Biomechanica Considerations. Med Sci Sports Exerc 2007;33(10):1701-1707. [http://dx.doi. org/10.1097/00005768-200110000-00014]

21. Fuller CW, Smith GL, Junge A, Dvorak J. The influence of tackle parameters on the propensity for injury in international football. Am J Sports Med 2004;32(Suppl 1):4353. [http://dx.doi.org/10.1177/036354650326128]

22. Williams S, Trewartha G, Kemp S, Stokes K. A meta-analysis of injuries in senior men's professional rugby union. Sports Med 2013;43(10):1043-1055. [http://dx.doi. org/10.1007/s40279-013-0078-1] 